\title{
Neoliberalising Bioethics: Bias, Enhancement and Economistic Ethics
}

\author{
KEAN BIRCH ${ }^{1}$
}

\begin{abstract}
In bioethics there is an ongoing debate about the ethical case for human enhancement through new biomedical technologies. In this debate there are both supporters and opponents of human enhancement technologies such as genetic improvements of cognitive abilities (eg, intelligence). The supporters argue that human enhancement will lead to healthier and therefore better lives, meaning that any delays to the introduction of such technologies is problematic. In contrast, the opponents argue that new technologies will not solve problems such as inequality and social justice. In order to overcome opposition to human enhancement, Bostrom and Ord have outlined a test to evaluate ethical arguments for "status quo bias" or what they call "intuitive judgements" in the assessment of human enhancement. This article is a response to their paper in which I raise a number of problems with their position, particularly with their "status quo bias" test and the incorporation of economistic thinking into their ethical arguments.
\end{abstract}

\section{Introduction}

The credit crunch that has resulted from deregulated financial markets, limited government oversight, and collapsing stock prices raises serious questions about the underlying assumptions of neoclassical economics, especially in their neoliberal variants. Neoliberalism takes many forms, but can be simplistically defined as an assumption that the market should be the core organizing institution in society; the market is supposed to provide (self-interested) individuals with freedom (of choice) at the same time that it enables the efficient allocation of resources. As such, different varieties of neoliberalism are sustained by a "common normative logic" that seeks to establish totalizing market-based institutions that encourage individualistic behaviour extending across all social systems around the world. ${ }^{2}$ The spread of this "market ethic", as David Harvey has characterized it, represents an ideological and political project highlighting the need to treat with suspicion the adoption or application of economic axioms to other areas of life, especially in the "fetish belief: that there is a technological fix for each and every problem". ${ }^{3}$

One area where such economistic thinking may prove problematic is in bioethical arguments in support of human enhancement technologies. Bioethics has been witness to numerous discussions about the nature of normal functioning and enhancement, ${ }^{4}$ which have, more recently, shifted towards presenting the ethical case for promoting human enhancement through new technologies, especially genetic technologies. ${ }^{5}$ The supporters and opponents of human enhancement have been split - somewhat simplistically perhaps - between "posthumanists" and "bioconservatives". A number of different people and groups can be identified as enhancement supporters ("posthumanists") including the likes of Gregory Stock, Lee Silver, Nick Bostrom, 
and Aubrey de Grey, as well as the Extropians, World Transhumanist Association (WTA), and Raelians. ${ }^{6}$ In bioethics, Carl Elliott identifies a number of major figures as supporters of human (especially genetic) enhancement including John Harris, Arthur Caplan, Glenn McGee and Julian Savulescu. ${ }^{7}$ The list of enhancement opponents ("bioconservatives") ranges across the political spectrum and includes the likes of Leon Kass, Francis Fukuyama, George Annas, Jeremy Rifkin and Bill McKibben. $^{8}$

The ethical case for human enhancement is based on the idea that to delay new technologies - such as genetically enhanced intelligence - has a detrimental effect on our lives, which could be better, healthier and longer with such interventions. In contrast, opponents have raised concerns around distribution, inequality and social justice that the individualistic focus on technological solutions to social problems does not address. In a recent article for the journal Ethics, ${ }^{9}$ Bostrom and Ord have tried to present the difference between the two camps as merely a difference in preference for the "known" over the "new": according to the authors, therefore, what is needed is "some way of adjudicating between the differing intuitions". ${ }^{10}$ In their paper they present a test to assess ethical arguments for "status quo bias" by drawing upon insights in behavioural economics. In particular, they want to counter arguments resting on "intuitive judgements" uninformed by "relevant facts" in ethical considerations of human enhancement, ${ }^{11}$ especially in relation to the genetic enhancement of intelligence, such as those made by Leon Kass with regards to the "wisdom of repugnance". 12 They therefore argue that a "cognitive bias...may be responsible for much of the opposition to human enhancement in general and genetic enhancement in particular". ${ }^{13}$

This article is a response to Bostrom and Ord's piece. Due to the limited space available for discussion, I focus on three specific problems with their argument, which I contend represents an example of the neoliberalisation of bioethics. First, I will analyse the two heuristic devices they present and raise a number of issues with them. Second, I will consider how the (partial) introduction of social scientific insights into their arguments has led them to construct an economistic ethic that incorporates certain problematic assumptions from neo-classical economic theory. More generally, supporters of human enhancement encounter such problems because their arguments are (and have to be) premised on the concept of individual choice - as opposed to the state intervention of eugenics - and would therefore be subject to market-based decision-making. This then leads to the third point: the adoption of economistic thinking in ethics has to adequately consider the problems associated with the externalities produced by individual self-interested actions (as accepted in such economistic thinking). In so doing, I want to reiterate the need to consider what I have previously termed "aggregate justice" in ethical arguments that centre on the individual in relation to human enhancement. ${ }^{14}$

\section{Whose Status Quo Bias?}

Bostrom and Ord contend that (bio)ethicists need to beware status quo biases in their arguments. They have constructed a heuristic device to identify such bias with the ostensible aim to remove bias from decision-making - at both individual and social 
level - so that it is only informed by the "relevant facts". According to Bostrom and Ord, the definition of a status quo bias is "an inappropriate (irrational) preference for an option because it preserves the status quo". ${ }^{15}$ Although they provide this clear definition of status quo bias, the authors' starting position is problematic in a number of respects.

First, they do not acknowledge that people might have an "inappropriate" or "irrational" preference for something that is good for individuals or society, but which also preserves the current socio-economic context (eg, equality, which can sometimes inhibit individualistic - as opposed to individual - choices). Second, and following on from the last point, they do not enter into discussion about what is good or bad per se - and therefore should be promoted - but instead concentrate on changes "producing something worse". ${ }^{16}$ This leaves aside the crucial question of how we assess whether something is good or bad. For example, if Bostrom and Ord had argued that a certain preference is in itself good - because it is rational to desire certain things (eg, equality) - this begs the question as to why "rational" preferences - ie, those based on "relevant facts" - are important since it would be better to determine a set of goods to promote in the first place. Third, they therefore seem to have started their argument with the assumption that there are a set of goods that are undisputed - eg, human enhancement - without exploring why these are important. In contrast, it would seem necessary to first consider why a thing itself (eg, equality, human enhancement etc) is good rather than develop a process for deciding which thing to choose through the creation of a heuristic device that can only consider the "rationality" of a decision.

In summary, Bostrom and Ord have put a greater stress on the process of arriving at a decision rather than on the (good or bad) preference embodied in the decision itself. Furthermore, Bostrom and Ord's argument does not consider how we evaluate whether something is good or bad since they focus explicitly on a linear evaluation of consequences (ie, "producing something worse") in human enhancement (eg, laser eye treatment is better than contact lenses which is better than glasses). This leaves open a number of questions about the heuristic device Bostrom and Ord have called the "reversal test". This test runs as follows:

"When a proposal to change a certain parameter is thought to have bad overall consequences, consider a change to the same parameter in the opposite direction. If this is also thought to have bad consequences, then the onus is on those who reach these conclusions to explain why our position is such that it cannot be improved through changes to this parameter. If they cannot do so, then we have a reason to suspect that they suffer from a status quo bias". 17

There are several initial problems with this test. First, it is based on conceptualizing each "parameter" as "continuous", ${ }^{18}$ which would be hard to postulate unless there was a specific quantitative gradient upon which to measure it and therefore an assumed equilibrium or static point that represents a perceived "optimum" for human enhancement (eg, intelligent versus stupid). This would then mean that Bostrom and Ord start their argument with an assumed good to which we should strive or else we end up "producing something worse". However, the assumed good has to be based upon present presumptions about what is "good" because we cannot know the future 
consequences of our decisions or the environment in which their effects are felt. Consequently such assumed goods are liable to be biased to the "status quo" - eg, we currently think that being smarter is a good idea, but we only think so because our current situation rewards intelligence. Second, and more fundamentally, the heuristic device appears to fail a test of logic. Its premise is that:

If (A) has an outcome (B)

And $(\mathrm{C})$ has the same outcome (B)

Then $(\mathrm{A})$ and $(\mathrm{C})$ must be the same.

Here $\mathrm{A}$ and $\mathrm{C}$ are presented as the same, rather than equally bad, because the test does not assess whether something is good or bad in itself. However, there is no reason to assume that $\mathrm{A}$ and $\mathrm{C}$ are qualitatively the same thing. For example, if enhancement leads to a certain outcome, as does degradation (both deliberate), they can lead to bad outcomes regardless of whether we perceive them as threatening a status quo position; eg, enhancement threatens equality, whilst degradation threatens justice. The only way they can be conceived qualitatively as the same thing is to assume that they exist upon a continuous gradient (eg, higher intelligence is better than lower intelligence, although it would be more apt to argue that intelligent ideas are better than less intelligent ideas rather than intelligence per se). Finally, it is difficult to see how we can expect in any decision-making process to be able to assess the "optimum" choice because we would need to assume that we have (or can have) access to complete information about all possibilities. This is a basic assumption in neoclassical economics, which reveals an underlying economistic approach that the authors have taken in their article.

Bostrom and Ord present a second heuristic test, the "double reversal test", ${ }^{19}$ which suffers from similar problems as the first. It can be characterized as follows:

If a "natural" factor reduces capacity (A) having a bad outcome (B) And human intervention counterbalances (C) the bad outcome so that it is made "neutral" (D)

And then if the "natural" bad outcome disappears (A1) and has a good outcome (E) because of the counterbalance (C)

Then human intervention counterbalances $(\mathrm{C} 1)$ the good outcome and has a neutral outcome (D1)

If we cannot justify second counterbalance $(\mathrm{C} 1)$ we should therefore intervene to produce good outcome (E) whether or not this is naturally reduced (A) or not.

Again the authors have confused several different things to arrive at their heuristic device. They equate different consequences along a continuum, once again, which enables them to contend that certain impacts are better than others, ignoring the possibility that they are qualitatively different. Ironically, one of the main assumptions throughout these arguments is that the present (ie, "status quo") is static in that it exists at a certain point on a scale. It has to be static for their arguments to work and to make the claim that "enhancement" (by definition) would be an improvement on the current situation. In contrast it would more reasonable to conceive of the present as a process that involves constant changes as people develop, 
adapt and relate to one another, altering both the physical and social world as they do so. Thus, advocating enhancement can be seen as taking a socially conservative position in relation to the understanding of society, particularly when it is based on economic principles that do not challenge the existing neoliberal orthodoxy of individualistic choice in "free" markets.

\section{Economistic Ethics}

Bostrom and Ord have based their ethical arguments on a theory drawn from behavioural psychology and used to explain economic activity. However, they have only referred to part of the theory and have ignored an important aspect. Although they present the evidence of people's preference for the "status quo", ${ }^{20}$ they fail to mention why people have such a preference. This preference results from the difference between how people experience loss and gain. For example, Richard Layard - writing as an economist - argues that loss has twice the impact on people's happiness, and their lives, as gain; therefore, loss-aversion has to be taken into account when considering (social) change. ${ }^{21}$ Unlike Bostrom and Ord, who see lossaversion as a problem with the "framing" of specific issues, ${ }^{22}$ the question of how people experience loss and gain would seem to be central to any ethical argument. Instead, by sidelining the issue of what constitutes good and bad, they do not need to address this aspect of the economic theory they seek to apply to bioethics and, in so doing, they incorporate an economistic approach in their arguments that is highly problematic.

The partial application of this social science theory to ethics is important for a number of reasons. First, if Bostrom and Ord want to apply such concepts to ethical arguments they need to address the whole theory rather than apply it in a limited fashion because they then miss out crucial elements that have a bearing upon ethical debates. For example, would the disruption caused by supporting the introduction of genetic enhancement technologies at the expense of other research or social programmes be justifiable if the gain from the former is unknown? Second, even if conceptualized as continuous variables, loss and gain would seem to have a very different ethical value from one another: this means that they are not necessarily commensurate. Third, ignoring the effects of changes to happiness and social meanings is problematic because it stems from conceptualizing humans as rational, self-interested actors; that is, the Homo economicus of neoclassical economic theory. Thus, it is debatable whether the assumption of rational calculation in economic theory is an adequate way to make such ethical judgements.

The adoption of rational calculation leads to an economistic ethic entailing a number of further problematic assumptions. First, we would need to assume that people have a choice over their health, which contradicts numerous studies pointing to the social, political and economic basis of health and well-being (eg, "postcode lottery" in healthcare). ${ }^{23}$ This is because the conceptualization of rational calculation requires that people indicate their preferences through their behaviour; for example, they choose better health by buying health insurance or private healthcare. In contrast, research on the social basis of health would suggest that the eradication of inequality would prove more beneficial than the introduction of enhancement technologies, 
especially if such technologies were distributed through "free" markets. The constraints imposed by the current capitalist system (eg, profit accumulation) would not produce the results that enhancement supporters wish to promote since the spread of such technologies would be subject to price rather than need.

Second, and more importantly, there is a subtle shift in emphasis from viewing the basis of behaviour as situated within social relationships (and therefore not purely individualized and rational) to viewing it as a consequence of our corporeality. For example, Bostrom and Ord argue that the genetic enhancement of particular traits (eg, intelligence) is the solution to "problems that [have] proved intractable to blind evolution" in that all we need to do is determine a "goal" before "working out what genetic modifications are necessary to attain it". ${ }^{24}$ Thus, our behaviour is seen as a consequence of our individual biological bodies, whether they are enhanced or not, which would affect our perception of responsibility. It is useful here to consider Jonathan Glover's distinction between logical and causal theories of responsibility; the former refers to an assessment based on action (eg, we give and therefore we are generous) and the latter to evaluations based on essentialist characteristics (eg, we are generous and therefore we give) ${ }^{25}$ Basing public policy and political economy on the latter view - as implied by enhancement supporters like Bostrom and Ord - leads to the view that people are incorrigible (eg, selfish, self-interested) and therefore that it is not possible to change their individual make-up since it is already fixed. Thus social change, including the amelioration of social problems, is no longer possible through social action, but only through self-interested individual decisions and the intervention of individually focused technological enhancements.

Finally then, this adoption of a causal view of behaviour can be seen as both a consequence and a cause of the focus on the introduction of technological interventions to solve social and ethical problems. As such it represents a divergence from the "normative commitment to judging and changing human behaviour" which Cahill argues "is, after all, what defines ethics". ${ }^{26}$ This produces a self-fulfilling prophecy in ethical arguments because certain arguments promote specific responses to ethical questions that foreclose other possibilities. ${ }^{27}$ For example, the promotion of technological enhancement is a costly enterprise that stretches across many years of basic research, product development and clinical testing: it is therefore only the target generation that receives the benefit, whereas social improvements would benefit all generations. To promote such intervention necessitates that there is support for these endeavours or they will fail. Enhancement supporters therefore have to promote technological solutions to social problems at the expense of other solutions in order for their ethical arguments to gain weight and hopefully bear fruit. However, this leads to the conceptualization of social problems in specific terms (ie, individualized and incorrigible views of behaviour) that naturalizes the ethical arguments they originally made, making them appear to be the only sensible option to pursue. ${ }^{28}$

\section{Economic Externalities and the Ethics of Enhancement}

Whilst there are some serious issues with adopting an economistic approach to bioethics, as I outlined above, the approach that Bostrom and Ord have adopted also entails an important and inherent contradiction. When considering the economic angle 
that Bostrom and Ord have taken in their argument, it is evident that there is some confusion between person-affecting and impersonal views of harm. ${ }^{29}$ In order to explore this fuzziness in their argument it is useful to draw on another concept from economics, that of externalities. According to Milton Friedman these are "the effect of a transaction ... on a third party who has not consented to or played any role in the carrying out of that transaction". ${ }^{30}$ In short, an externality is the harm (and good) that an action has on those not directly involved in a transaction (or activity). For example, the enhancement of intelligence in children may produce a harmful (or negative) externality such as the need for higher taxation of adults to cover the necessary increased expenditure on education for enhanced children - meaning cuts elsewhere whilst also a good (or positive) externality such as an increase in knowledge once the children are adults. However, it is important to consider how these externalities have different effects at the individual and aggregate scales.

The first thing to consider is that a harmful (or negative) externality is beneficial for those directly involved in the activity because it enables certain costs involved in the activity to be passed onto other people. Such negative externalities can have both individual and aggregate effects. For example, intelligence enhancement benefits the person who is being enhanced (eg, better grades, job, etc) and the person providing the technology (eg, profits, extra research funding, etc); however, it can harm other individuals who lack the associated advantages of the enhancements as well as the aggregate population through increased educational expenditure, and cuts to other programmes, that are needed to support the enhanced person. In contrast, positive externalities are largely restricted to aggregate effects because any individual advantages are likely to be internalized as part of the transaction itself: that is, the transaction is a consequence of two parties seeking to gain an individual benefit from their activity (eg, better grades or job on the one hand and profit or research funding on the other). Along with bearing in mind these aspects of externalities, it is also crucial to remember that it is extremely difficult (if not impossible) to accurately predict the aggregate effects of particular actions, whether they are meant to affect an individual or an aggregate population. ${ }^{31}$

The preceding discussion relates to Bostrom and Ord's arguments in a number of ways that illustrate the extent to which they have confused person-affecting and impersonal harms (and benefits). In producing an economistic ethic they have to make a person-affecting argument because of the underlying assumption in economic theory that individuals are both rational and self-interested. However, in seeking to avoid a status quo bias in their own arguments, they cannot justify their ethical position with the individual benefits of enhancement (eg, intelligence-enhanced people will have better lives than others), because such benefits are dependent upon the current context which rewards particular attributes. Instead they have to present the aggregate good (or externality) of enhancement as the basis for their moral argument (eg, society will be more productive as the result of intelligence enhancement). Their argument would, therefore, appear to be underpinned by person-affecting reasoning, but justified by an impersonal harm perspective.

More problematically, however, Bostrom and Ord have extrapolated from the personal benefits of enhancement in their vision of the societal benefits that 
enhancement would bring. This is necessary because there is no way to know what the aggregate effects of enhancement will be, whether they are positive, negative or both. For example, their argument depends on the assumption that enhanced people will lead better lives and therefore that it is ethical to pursue enhancement technologies at the aggregate population scale. However, the assessment of the benefits to each individual of enhancement technologies can only be made in relation to the current context because it is not possible to predict what would be advantageous in future contexts. In this sense, Bostrom and Ord have themselves given in to an analytic - as opposed to normative - status quo bias (ie, basing a judgement of the future on current trends). ${ }^{32}$

The relationship between person-affecting and impersonal harms in Bostrom and Ord's argument are further problematized when considering who will actually benefit from any change, specifically when it concerns human enhancement. The people affected by a change (ie, when there is no status quo bias) can only be considered in impersonal terms because they are not the same people as those who would not be affected by a change (ie, when there is a status quo bias). This results from Parfit's "non-identity problem". ${ }^{33}$ Those people who are changed (eg, enhanced) can only be conceptualized in impersonal terms because we cannot know what will benefit and harm future generations; we can only extrapolate from current trends. Furthermore, we cannot predict the future context of individuals, which may be radically different from our own, or the impact of socio-technical developments on individuals. In contrast, those people not affected by change (eg, non-enhanced) can be conceptualized in both impersonal and person-affecting terms because we can extrapolate from current benefits and harms they might encounter. Thus Bostrom and Ord's argument rests on conceptualizing impersonal benefits for future generations that are derived from a totally different population set (ie, current generations) in person-affecting terms.

\section{Conclusion}

As mentioned in the introduction, I have previously argued that we need to consider human enhancement in terms of "aggregate justice" rather than person-affecting terms. ${ }^{34}$ The decisions of individuals, especially when conceptualized in economic (ie, self-interested and rational) terms, lead to problematic consequences for aggregate populations. The discussion of externalities in the previous section further highlights these issues. Whilst negative externalities may impact on both individuals and populations, positive externalities are largely limited to population impacts. In this sense, any beneficial consequences of human enhancement would not provide benefits to individual people (eg, better work, well-being etc) because they would not be the same people who would have existed were there no enhancement. Rather, any positive impacts would only benefit the aggregate population and only in an abstract way (eg, greater production of knowledge). In contrast, the negative externalities of human enhancement would impact on both individuals and aggregate populations in that individual people would be at a disadvantage if they did not acquire enhancements and aggregate populations could suffer from the excessive costs of both developing new technologies and their subsequent implementation. 
Recently the promotion of human enhancement (at least in the UK) - whether through genetic technologies or other means - has become a popular topic within think tanks, ${ }^{35}$ newspaper discussions, ${ }^{36}$ and academic conferences. ${ }^{37}$ Such discourses illustrate the desire to ameliorate social problems through technological interventions. Furthermore, these popularization efforts by enhancement supporters highlight that their aim is both a political and ethical agenda in that they seek to encourage the development and uptake of technological enhancement generally while simultaneously justifying these enhancements and their development as ethical choices. It is crucial to examine the theoretical underpinnings of these arguments because the incorporation of economistic thinking in our reasoning raises several concerns as I have sought to highlight in this article. Such neoliberalisation of bioethics can prove problematic because we have to ask, as Richard Ashcroft does, whether "major public investment in technologies which can only benefit a tiny minority of the already advantaged is just". 38

There is also a more general problem with the concept of human enhancement itself when considering a status quo bias. The only point to enhancement, in personaffecting terms, is if the enhanced trait remains the same for everyone else and that the trait is a contestable attribute in which bias already operates; otherwise why enhance if there is no benefit? Beneficial aspects of enhancement come from the bias that already exists in the socio-technical context in which the enhancement is made. For example, intelligence is only worth enhancing if it provides a benefit, but it is only beneficial because of existing social bias. Thus intelligent people get to work in nice environments for nice organizations in nice occupations. The rhetoric used by enhancement supporters has to be considered in light of these issues as well as the economistic turn in ethical discourse that accompanies the focus on means (eg, rational decision-making) rather than ends in such debates. ${ }^{39}$

\footnotetext{
${ }^{1}$ Centre for Public Policy for Regions, University of Glasgow kean.birch@lbss.gla.ac.uk

${ }^{2}$ P. Cerny. Embedding Neoliberalism: The Evolution of a Hegemonic Paradigm. The Journal of International Trade and Diplomacy 2008; 2(1):10-11.

${ }^{3}$ Harvey, D. 2005. A Brief History of Neoliberalism. Oxford: Oxford University Press, p.68.

${ }^{4}$ For example, see N. Daniels. Normal Functioning and the Treatment-Enhancement Distinction. Cambridge Quarterly of Healthcare Ethics 2000; 9: 309-322; Also E, Parens, ed. 1998. Enhancing Human Capacities. Washington, DC: Georgetown University Press.

${ }^{5}$ F. Baylis and J. Robert. The Inevitability of Genetic Enhancement Technologies. Bioethics 2004; 18(1):1-26; N. Bostrom. Human Genetic Enhancements: A Transhumanist Perspective. Journal of Value Inquiry 2003; 37:493-506; N. Bostrom and R. Roache. 2007. Ethical Issues in Human Enhancement: In Ryberg J, ed. New Waves of Applied Ethics. Palgrave Macmillan; A. Caplan. Is It Ethical to Use Enhancement Technologies to Make Us Better than Well? PLoS Medicine 2004; 1(3):172-175; A. Miah. 2004. Genetically Modified Athletes. Abingdon: Routledge; J. Savulescu. New breeds of humans: the moral obligation to enhance. Reproductive BioMedicine Online 2005; 1(1):3639.

${ }^{6}$ L. Winner. 2005. Resistance is Futile: The Posthuman Condition and Its Advocates: In S, Baillie \& T, Case, eds. Is Human Nature Obsolete? London: MIT Press: 385- 408.

${ }^{7}$ C. Elliott. The Soul of a New Machine: Bioethicists in the Bureaucracy. Cambridge Quarterly of Healthcare Ethics 2005; 14: 379-384.

${ }^{8}$ N. Bostrom. In Defense of Posthuman Dignity. Bioethics 2005; 19(3): 202-214; N. Bostrom. A History of Transhumanist Thought. Journal of Evolution and Technology 2005; 14(1): 1-25; R. Macklin. The New Conservatives in Bioethics. Hastings Center Report 2006; Jan-Feb: 34-43.
} 
${ }^{9}$ N. Bostrom and T. Ord. The Reversal Test: Eliminating Status Quo Bias in Applied Ethics. Ethics 2006; 116: 656-679.

${ }^{10}$ Bostrom \& Ord, op. cit., note 9, p.664.

${ }^{11}$ Ibid, p.657.

${ }^{12}$ L. Kass. The Wisdom of Repugnance. New Republic 1997; 216(22): 17-26.

${ }^{13}$ Bostrom \& Ord, op. cit., note 9, p.657-8.

${ }^{14} \mathrm{~K}$. Birch. Beneficence, Determinism and Justice: An Engagement wit the Argument for the Genetic Selection of Intelligence. Bioethics 2005; 19(1):12-28.

${ }^{15}$ Bostrom \& Ord, op. cit., note 9, p.658.

${ }^{16}$ Ibid, p.664.

${ }^{17}$ Ibid, 664-5.

${ }^{18}$ Ibid, p. 665.

${ }^{19}$ Ibid, p. 673.

${ }^{20}$ Ibid, p.658-662.

${ }^{21}$ Layard, R. 2006. Happiness: Lessons from a New Science. London: Penguin Books: pp.141-142.

${ }^{22}$ Bostrom \& Ord, op. cit., note 9, p.661.

${ }^{23}$ N. Daniels, B. Kennedy and I. Kawachi, . Why Justice is Good for Our Health: The Social

Determinants of Health Inequalities. Daedalus 1999; 128(4): 215-251; N. Daniels. Normal Functioning and the Treatment-Enhancement Distinction. Cambridge Quarterly of Healthcare Ethics 2000; 9: 309322; D. Callahan. Medicine and Market: A Research Agenda. Journal of Medicine and Philosophy 1999; 24(3): 224-242.

${ }^{24}$ Bostrom \& Ord, op. cit., note 9, p.666.

${ }^{25}$ J. Glover. 1970. Responsibility. London: Routledge \& Kegan Paul.

${ }^{26}$ L. Cahill. Biotech and Justice: Catching Up with the Real World Order. Hastings Center Report 2003; Sept-Oct: 42.

${ }^{27}$ K. Birch. Introduction: Biofutures/Biopresents. Science as Culture 2006; 15(3): 173-181.

${ }^{28}$ A. Hedgecoe and P. Martin. The Drugs Don't Work: Expectations and the Shaping of Pharmacogenetics. Social Studies of Science 2003; 33(3): 327-364.

${ }^{29}$ Holm and Takala note this problem in the rhetoric of 'automatic escalator' arguments generally: S. Holm and T. Takala. High hopes and automatic escalators: a critique of some new arguments in bioethics. Journal of Medical Ethics 2007; 33: 1-4.

${ }^{30}$ Quoted in J. Bakan. 2004. The Corporation. London: Constable.

${ }^{31}$ P. Ormerod. 2005. Why Most Things Fail ... And how to avoid it. London: Faber and Faber.

${ }^{32}$ My thanks to one of the anonymous referees for highlighting the distinction between 'analytic' and 'normative' status quo bias.

${ }^{33}$ D. Parfit. 1987. Reasons and Persons. Oxford: Clarendon Press.

${ }^{34}$ Birch, op. cit., note 14 .

${ }^{35}$ P. Miller and J. Wilsdon. 2006. Stronger, longer, smarter, faster. In: P, Miller and J, Wilsdon, eds. Better Humans? London: DEMOS: 13-27.

${ }^{36}$ Several examples include: J. Wilsdon. Who would not seize the chance to live to 150 ? The Financial Times 2006; 7 Feb; G. Lawton. The new incredibles: Enhanced humans. New Scientist 2006; 13 May; M. Bunting. There is no stop button in the race for human re-engineering, The Guardian 2006; 30 Jan.

${ }^{37}$ For example, Tomorrow's People, University of Oxford, March 2006 (www.martininstitute.ox.ac.uk/jmi/forum2006).

${ }^{38}$ Ashcroft, R. 2003. American biofutures: ideology and utopia in the Fukuyama/Stock debate, Journal of Medical Ethics 29: 61.

${ }^{39}$ Holm and Takala, op.cit., note 29. 